\title{
Erratum to: A model for adapting 3D graphics based on scalable coding, real-time simplification and remote rendering
}

\author{
Marius Preda $^{1}$ - Paulo Villegas ${ }^{2}$ - Francisco Morán ${ }^{3}$ - Gauthier Lafruit ${ }^{4}$. \\ Robert-Paul Berretty ${ }^{5}$
}

Published online: 14 July 2016

(C) Springer-Verlag Berlin Heidelberg 2016

\section{Erratum to: Vis Comput (2008) 24:881-888 \\ DOI 10.1007/s00371-008-0284-2}

The spelling of Francisco Morán's name was incorrect.

His correct name is given above as well as in his biography.

We apologize for this mistake.

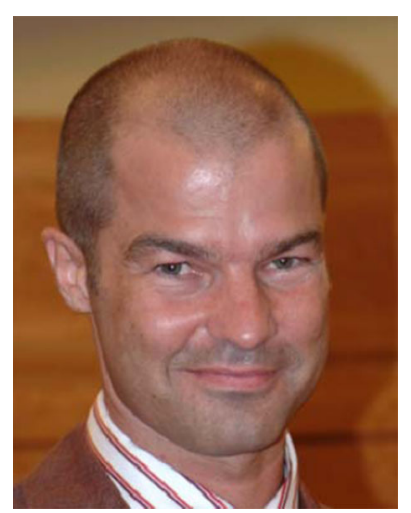

Francisco Morán received the degrees of Telecommunication Engineering and Ph.D. in Telecommunication, both from the UPM (Universidad Politécnica de Madrid, Spain) in 1992 and 2001, respectively. Since 1992 he is a researcher at UPM becoming in 2002 a full-time Associate Professor in the knowledge area of Signal Theory and Communications. His research interests include modeling, coding, transmission and visualization of $3 \mathrm{D}$ objects. He has been and is actively involved in projects funded by the RACE, ACTS and IST Programs of the European Commission.

\section{doi: $10.1007 / \mathrm{s} 00371-008-0284-2$}

\author{
Marius Preda \\ Marius.Preda@int-evry.fr \\ Paulo Villegas \\ Paulo@tid.es \\ Francisco Morán \\ Francisco.Moran@upm.es \\ Gauthier Lafruit \\ Gauthier.Lafruit@imec.be \\ Robert-Paul Berretty \\ Robert-Paul.Berretty@philips.com \\ 1 Institut TELECOM, TELECOM et Management SudParis, \\ ARTEMIS, Evry, France \\ 2 Telefónica I+D, Madrid, Spain \\ 3 Universidad Politécnica de Madrid, Madrid, Spain \\ 4 Interuniversitair Micro Electronica Centrum, Leuven, \\ Belgium
}

5 Philips Research, Eindhoven, The Netherlands

The online version of the original article can be found under 